\title{
O real e o imaginário no processo de construção do conto infantil
}

\author{
The real and the imaginary in the process of constructing the fairy tale
}

\author{
Deolinda Maria Soares de CARVALHO* \\ Universidade Federal do Acre (UFAC) \\ Maria José Silva Morais COSTA** \\ Universidade Federal do Acre (UFAC) \\ Jocilene Silva de ANDRADE***
}

Secretaria de Estado de Educação do Acre (SEE)

RESUMO: O presente artigo mostra como o imaginário de um grupo de estudantes dos cursos de Letras e de Pedagogia da Universidade Federal do Acre, em Cruzeiro do Sul, Acre, preserva um vínculo com as narrativas tradicionais, ao mesmo tempo em que busca formas de inovação. Para tanto, tomou o livro Um fantástico mundo João, produção de um grupo de alunos, como objeto de análise, cujo esteio teórico-metodológico está em Vladmir Propp (1984), Joseph Campbell (1997) e Gilbert Durand (1997). Constatou-se a capacidade das narrativas em atravessar vários discursos, sejam históricos, religiosos ou políticos, vindos de lugares e épocas distintas, para retornarem em um outro momento, embora, muitas vezes, com novas roupagens. O protagonista João é a reprodução do herói clássico dos contos de fadas que após uma busca ganha como prêmio a realização plena de seu desejo.

PALAVRAS-CHAVE: Conto Infantil. Construção. Imaginário.

\begin{abstract}
This article introduces how the imaginary of a group of students of the modular courses of Lettersand Pedagogy of the Federal University of Acre, in Cruzeiro

\footnotetext{
* Doutora em Educação pela Universidade Federal Fluminense, Niterói/Rj. E-mail: deofogo@bol.com.br

** Doutora em Educação pela Universidade Federal Fluminense, Niterói/Rj. E-mail: zezamorais@gmail.com

*** Especialista em Língua Portuguesa pela Universidade Federal do Acre, Cruzeiro do Sul/Acre. E-mail: jocilene@gmail.com
} 
do Sul, Acre, preserves a link with the traditional narratives, while at the same time seeking forms of innovation. For that, he took the book Um Fantástico Mundo João, produced by a student, as object of analysis, whose theoretical and methodological mainstay is in Vladmir Propp (1984), Joseph Campbell (1997) and Gilbert Durand (1997). The narratives' ability to cross various discourses, whether historical, religious or political, from different places and epochs, to return at another time, although often with new clothes, was verified. The protagonist João is the reproduction of the classic hero of the fairy tales that after a search wins as a prize the full realization of his desire.

KEY-WORDS: Childhood tale. Construction. Imaginary.

\section{Introdução}

O presente artigo tem como objeto de análise o livro Um Fantástico Mundo João ${ }^{1}$, uma de muitas produções elaboradas pelos alunos dos cursos modulares de Letras Português e Pedagogia, da Universidade Federal do Acre, do campus Floresta, em Cruzeiro do Sul. Foram construídos contos, fábulas, lendas, poesias e até mesmo um romance, obtendo-se assim um pequeno acervo bibliográfico de autores discentes, amadores, mas, mesmo assim, importantes, por conterem marcas literárias que atraem o olhar de estudiosos. Um Fantástico Mundo João é um conto infantil, sendo escolhido para análise por travar um diálogo com narrativas infantis tradicionais e com um romance da literatura brasileira, O Grande Mentecapto, de Fernando Sabino, e, ainda, por apresentar uma estrutura formal parecida com a dos contos considerados de caráter maravilhoso.

Pretende-se mostrar como o imaginário desses estudantes, de certa forma, mantém um laço com esse tipo de narrativa tradicional, ao mesmo tempo em que busca

\footnotetext{
${ }^{1}$ Este livro foi uma criação coletiva produzida em 2002 por acadêmicos do curso de Letras Português da Universidade Federal do Acre - Câmpus Floresta em uma atividade da disciplina Literatura Infanto Juvenil. São eles: Marcos Antonio Copetti, Maria Anizete Lima da Silva, Maria José Correia e Alciânia Almeida Sampaio.
} 
elementos novos em outras formas de produção, adaptando, assim, o herói aos mais diversos contextos. Deste modo, o estudo encontra suporte teórico-metodológico, principalmente, em Vladmir Propp (1984), que disponibiliza elementos à análise funcional comparativa, possibilitando um estudo estrutural que permite a identificação das funções básicas dos contos maravilhosos; em Joseph Campbell (1997), por apresentar o herói em suas mil faces; e nos estudos fenomenológicos de Gilbert Durand (1995), por favorecer a localização de alguns símbolos que foram desvelados, também, a luz de Chevalier e Gheerbrant (2009).

A literatura, assim, pode ser atemporal, mantendo vivas através do tempo as estórias que tocam a alma humana. Do mesmo modo, (re)inventa situações que, embora ficcionais, nascem da realidade do homem. Eis aí a chave para decifrar o enigma da identificação e aceitação de tantas produções clássicas na atualidade. Não é sobre o homem que falam os contos das Mil e Uma Noites ou da Gata Borralheira? O real e o imaginário criam um mundo que requer uma percepção mais apurada, provocando uma reflexão para o surgimento de algo novo.

\section{Imaginário e literatura}

Quando mencionamos a palavra imaginário nos vem logo a ideia de imagem, pois sua configuração nos aproxima dessa outra estrutura vocabular. Ao observarmos sua composição, vemos que nela há algo de intrigante, pois -ário é um sufixo que denota coletivo ou coleção. Assim, imaginário deve significar uma coleção de imagens. Para Hillman (1997), a imagem fala como o próprio mundo, de forma concreta e, também, inclusive sensorial. Pode-se pensar, portanto, que a imagem tem corpo por evocar fantasias em nossas mentes. Um estado de dor, por exemplo, pode ser representado por um olho roxo, ou mesmo um coração partido ao meio. Percebe-se com isso que pelas imagens transitam símbolos que são significados e ressignificados em seus contextos culturais e sociais.

Com isso, a noção de imaginário se amplia mostrando-se como "um sistema 
dinâmico aberto em que 'agrupamentos sistêmicos de imagens comportam uma espécie de auto-organização, autopoiésis, abrindo sem cessar o imaginário à inovações, transformações e recriações” (TEIXEIRA e ARAÚJO, 2011, p.41). Segundo os estudos de Durand (1995), o imaginário funciona como um organizador de todo o pensamento humano que se constitui por meio de uma herança imagética de configuração mítica. A partir dessa perspectiva, podemos pensar como o conto tradicional infantil se (re)organizou, guardando muito de sua estrutura inicial ao mesmo tempo em que encontrou novas motivações temáticas e organizacionais que permitem um trânsito entre o real e o imaginário. Jaqueline Held nos diz “O poeta é aquele para quem não existe um único mundo. $\mathrm{O}$ mito deve sua força à pluralidade das leituras. Uma vida humana é uma ficção que o homem inventa à medida que caminha." (1980, p. 18)

Os contos infantis guardam algo de sua origem oral, rememorando medos, aventuras e, também, situações engraçadas experimentadas pelo homem em tempos primordiais. Não será por isso que gostamos de estórias de monstros como, também, daquelas que mostram a superação e vitória de uma criança abandonada frente aos perigos da orfandade e da pobreza? Para Campbell, "É próprio do mito como do conto de fadas, revelar os perigos e técnicas específicos do sombrio caminho interior que leva da tragédia à comédia.” (1997, p. 35) Embora a construção narrativa parta de uma instância psíquica, seu reflexo reverbera no mundo real. Held (1980) nos mostra isso afirmando que ter medo do lobo, por exemplo, ajudará a criança a ter menos medo de seus pais. Essas narrativas, assim, sob essa perspectiva, funcionam como uma iniciação que preparará a criança para o enfrentamento do mundo, permitindo seu amadurecimento psicológico e emocional. Isso mostra que o homem cria suas narrativas porque precisa sonhar, tecendo fios que interligam o real e o imaginário em uma trama condutora de sua salvaguarda e felicidade.

\section{2. $O$ conto em perspectiva}

A origem do conto está na tradição oral. Segundo Carvalho (2001), o conto 
literário surge do encontro do popular e do erudito como uma elaboração artística que não se afasta totalmente de sua origem. Assim, por exemplo, o contista pode lançar mão de componentes presentes nos contos populares. Essa forma narrativa ainda guarda a brevidade e a concisão original. O conto literário, portanto, apresenta-se sob uma perspectiva de várias faces, podendo misturar-se, inclusive, a outros gêneros e formas. No dizer de Costa, "este gênero opera a soma dos traços da tradição oral com a elaboração estética e escorrega do domínio coletivo da linguagem para o universo do estilo individual de um escritor e de suas idiossincrasias literárias" (2013, p. 59). O conto infantil também vem dessa mesma tradição. Contudo, seu formato como conhecemos hoje foi adquirido a partir do final do século XVIII e início do século XIX, quando o francês Charles Perrault, os alemães Jacob e Wilhelm Grimm e o dinamarquês Hans Christian Andersen pesquisaram, recolheram e adaptaram histórias contadas por camponeses criados em comunidades de forte tradição oral. Histórias tradicionais como Chapeuzinho Vermelho, Cinderela, Branca de Neve, João e Maria, A Bela Adormecida dentre outras, não eram, em sua origem, exatamente histórias infantis, sendo contadas de forma rústica, sem camuflar inclusive detalhes picantes e violentos. Campbell mostra que "o terror é o sentimento que toma conta da mente na presença de tudo o que é grave e constante nos sofrimentos humanos e que a une à causa secreta" (1997, p.32). Mostra assim que a tragédia é o sinal de desapego às coisas e que tudo está em mudança, em um princípio catártico. Nesse sentido, o final feliz do conto de fadas, por exemplo, mostra uma transcendência da tragédia universal do homem.

A superação da condição dramática do homem mostra-se assim no próprio tratamento dado às novas versões dos contos que se transvestem de forma mais leve e delicada. Isso se justifica na própria condição da criança, que passa, em meados do século XIX, a ser vista de modo diferente, passando a infância a ser considerada uma etapa especial do desenvolvimento humano. Deste modo, foi necessário fazer um trabalho de adaptação nos textos resgatados, a fim de torná-los acessíveis às famílias e adequados ao público infantil. Flávia Ribeiro menciona que a estória de Chapeuzinho Vermelho, por exemplo, continha, em sua origem, cenas de muita violência: "E o lobo 
matava a vovó, e enchia uma jarra com seu sangue e fatiava sua carne. Quando a menina chegava, ele, já travestido, mandava que ela se servisse do vinho e da carne..." (2005, p. 20). Ribeiro não explica a origem da violência, contudo a sugere como um ingrediente da narrativa usado com o fim de prender a atenção dos espectadores. Na versão dos Grimm, vê-se uma edulcoração da trama, que se apresenta bem mais leve e romantizada por meio até mesmo de um final feliz.

No Brasil, é, principalmente, com Monteiro Lobato que a narrativa infantil ganha espaço e notoriedade, sendo ele considerado o maior clássico do gênero ${ }^{2}$. $\mathrm{O}$ autor se destaca não apenas por escrever livros para crianças, mas por conseguir criar um universo para elas a partir de diversas motivações, com o rico acervo da literatura clássica infantil de caráter maravilhoso, o folclore brasileiro e até mesmo a realidade de sua infância, reconstruindo suas aventuras e ficcionalizando personalidades reais. A partir do diálogo entre o real e o imaginário, criou as estórias que fervilharam a mente de gerações, apresentando personagens marcantes como o Saci, a Cuca e o Marquês de Sabugosa.

A interação entre o real e o imaginário e o perfil multifacetado do conto lançam esse tipo de narrativa ao encontro da teoria do dialogismo, de Bakthin (2008), que defende a ideia de que o diálogo é uma característica inata à linguagem. Dessa forma, as relações dialógicas não se dão unicamente através do diálogo face a face. Ao contrário, existe uma dialogização interna da palavra, que é perpassada sempre pela palavra do outro. Segundo Aldrigue (1998), o dialogismo é uma relação de diálogo entre discursos, seja num segmento discursivo ou textual, podendo aparecer no texto através da interdiscursividade ou da intertextualidade:

A interdiscursividade é constitutiva de qualquer discurso e está no inconsciente do sujeito, a intertextualidade é a retomada consciente, intencional da palavra do outro pelo sujeito, é a presença do outro de forma

\footnotetext{
${ }^{2}$ Mesmo com a polêmica que aponta racismo e discriminação na construção dos personagens de Lobato, trazida pelo olhar às cartas do autor e publicizado por vários veículos midiáticos, dentre eles a Revista Bravo e A folha de São Paulo, não podemos deixar de considerá-lo como o precursor do gênero.
} 
explícita, embora não-marcada, no discurso da variante intertextual. (Aldrigue, 1998, p.96).

Isso significa dizer que para o enunciador construir um discurso leva em conta o discurso de outrem e o incorpora ao seu. No caso da intertextualidade, faz-se o processo de incorporação de um texto em outro, seja para reproduzir o sentido incorporado, ou para transformá-lo. O conto de fadas Cinderela, por exemplo, parece ser recontado eternamente, até mesmo por meio da linguagem televisiva das novelas, onde a gata borralheira, muitas vezes, usa jeans e mora no subúrbio de uma grande cidade.

O Fantástico Mundo de João também dialoga com outras obras, reconstruindo figuras e readaptando situações. O conto relata a estória de um menino de rua, sonhador e poeta, cujo, principal desejo era conhecer a biblioteca de sua cidade. Certo dia, encheu-se de coragem e resolveu finalmente adentrar naquele local. Na ocasião, conheceu três crianças e estas se tornaram suas amigas e passaram a apresentar-lhes cada espaço da biblioteca. Enquanto João, deslumbrado, observava minuciosamente cada detalhe, sofreu a acusação de derramar refrigerante em um dos livros de uma importante coleção literária. Após esclarecido o mal entendido, o menino foi inocentado e adotado pela diretora daquele estabelecimento.

Inicialmente, destaca-se o título do livro que é bastante significativo, abrindo espaço para diversas representações no universo dos textos infantis. O termo fantástico vem da palavra latina phantasticu, que significa fantasia. Refere-se a algo que é criado pela imaginação, não existindo de verdade. Assim, logo de início o leitor é convidado a aproximar-se do universo ficcional, se distanciando da realidade. A palavra mundo, segundo o dicionário Aurélio, possui várias acepções, cabendo aqui o sentido de tudo que existe no universo, neste caso, no universo do imaginário. João é um nome próprio de origem hebraica e significa a graça do Senhor. Transmite uma aparência comum, mas que a ênfase da vocalização, em português, sugere força e segurança.

Parece ser viável uma breve reflexão em torno do nome do personagem central "João - revira mundo". Foram localizados, em alguns contos tradicionais, principalmente, dos irmãos Grimm, personagens chamados João, como é o caso da 
história de João bobo, O casamento de João, João Ouriço, João Joga tudo, dentre outros. Nestes contos, o perfil do personagem João se assemelha bastante com o herói do conto Um Fantástico Mundo João. Em todos os casos o personagem João aparece como uma pessoa solitária e triste, porém, capaz de alimentar sonhos e desejos realizados no final da trama. Esse nome, dado a tantos heróis, recebe uma significação especial quando acrescido à expressão "revira mundo". O verbo revirar significa virar pelo avesso, remexer. Esse era o grande sonho do menino enquanto observava, silencioso, a biblioteca. Neste conto, são colocados mundos bastante distintos. O primeiro, o mundo real onde o garoto vive. A rua é seu lar e demonstra escancaradamente todas as inseguranças e desconfortos. Um lugar de solidão, mas mesmo assim é o local onde o personagem João consegue expressar-se e definir-se. O segundo, o mundo fantástico, aquele que só existe na fantasia e, no imaginário do ser humano, é capaz de povoar a mente tanto do poeta quanto do leitor. Somente o poeta é capaz de revirar mundo, ir mais além e trazer para sua poesia os sonhos, mesmo aqueles inimagináveis.

A biblioteca pode ser compreendida como um lugar de indefinição, de travessia. Não é a casa nem o local de trabalho ou estudo. Também não é o lugar da insegurança e do desconforto. Seria um lugar entre, uma fronteira, um caminho entre o mundo da rua e o mundo da imaginação, onde as possibilidades de elaboração do eu se expandem. É nesse entremeio que João Revira-mundo encontra a si mesmo e seu espaço de simbolização. Jorge Luis Borges (1984), ficcionista argentino de primeira ordem, no conto La biblioteca de Babel, reflete a respeito da acepção de biblioteca total. Seria um lugar onde todos os livros são possíveis, inclusive os não escritos ainda. A biblioteca, no dizer do autor seria o universo. Parece ser essa a percepção de João, a pequena biblioteca de sua cidade ganha, em seu imaginário, a acepção de universo de si. É, assim, lugar de abrigo de combinação de signos para forjar um eu. Lugar de guardar livros, ela ganha um significado importante na narrativa.

O livro é sobretudo, se passamos a um grau mais elevado, o símbolo do 
universo: O universo é um imenso livro, escreve Mohyddin ibn-Arabi... Se o universo é um livro, é que o livro é a revelação e, portanto, por extensão, a manifestação (CHEVALIER e GHERBRANT, 2009, p. 555).

De acordo com o Dicionário de símbolos, tanto a biblioteca como o livro são metáforas do universo. Dialogando com Borges, todos nós seríamos caracteres desse livro total. Todo o mundo revirado por João seria a composição desse livro-vida. Talvez essa seja a razão por que o espaço da biblioteca é tão encantador ao protagonista de nossa história.

O livro Um Fantástico Mundo João dialoga ainda com uma obra da Literatura Brasileira, O Grande Mentecapto, de Fernando Sabino. Em ambos os casos se percebe que os autores elaboram uma trama com a nítida intenção de deixar em evidência as pessoas humildes, simples e puras. No romance de Fernando Sabino, o herói Geraldo Viramundo é louco, desprovido de bens materiais, vagabundo e idealista. Já na produção discente, o personagem João Revira-mundo é pobre e sonhador, porém, a característica comum aos dois personagens é a solidão. Um diferencial entre as duas produções são os destinatários: $O$ Grande Mentecapto, um clássico da literatura para o leitor adulto, enquanto O Fantástico Mundo João tem como alvo os leitores infantis. Além disso, o cenário onde se sucedem as tramas em cada livro também é distinto. Em O Fantástico Mundo João, tudo acontece na única praça da cidade e em seguida numa biblioteca. Já no livro $O$ Grande Mentecapto, os acontecimentos se dão em espaços abertos e fechados, inclusive em cidades diferentes. A forma romanesca favorece a narrativa com um maior fôlego e complexidade, visto que esta apresenta uma narrativa longa, envolve um número considerável de personagens e maior número de conflitos, onde tempo e espaço são bem mais dilatados. Contudo, tanto o romance quanto o conto em questão mostram a inquietação do homem como algo universal. O desejo de ter uma família, conforto, moradia, educação, uma vida digna, são necessidades básicas para o ser humano considerar-se feliz em qualquer tempo e espaço, como também o são os sonhos, os medos e as dúvidas. O desejo de João, no entanto, iria para além disso, uma vez que sua busca se dá na biblioteca, parece haver um interesse pelo conhecimento de 
outros mundos.

Em relação ao aspecto estrutural, esse conto apresenta uma sequência narrativa muito próxima a dos contos tradicionais de caráter maravilhoso. Percebe-se uma sustentação por meio das trinta e uma funções apresentadas por Vladimir Propp (1984). Foram identificadas na narrativa Um Fantástico Mundo João quatorze das funções identificadas por Propp, e estas se tornaram evidentes no decorrer do texto, muito embora não obedeçam à sequência sugerida pelo teórico. Algumas funções tiveram sua ordem alterada, sem, no entanto, comprometer o curso da narrativa. Sendo assim, o enredo foi construído de maneira a demonstrar o entrelaçar dos fatos já a partir da situação inicial ${ }^{3}$ conforme o fragmento a seguir:

João tinha uma baita cabeça e dentro dela, um milhão de idéias; um milhão de mundos diferentes saltavam, atrevidos, querendo liberdade. Corria um boato na cidade que dizia João ser filho do amor incerto entre a lua e o sol. Seus amigos da rua o chamavam de João - sonhador, João revira-mundo, João falador (COPETTI, 2002, p. 7).

Através da situação inicial, apresenta-se o futuro herói ou o protagonista da história. No conto $O$ Fantástico Mundo João foi feita uma breve descrição do principal personagem. Com isso, é possível o leitor perceber em torno de quem irá pairar a trama. Após esta situação inicial, apresenta-se a função afastamento, momento em que os afazeres deixam transparecer que o garoto vive sem família e tem como lar a própria rua, porém, é justamente neste espaço e ambiente que o garoto alimenta a esperança, enquanto fala sozinho, revela a capacidade de expressar-se e sonhar com uma vida melhor.

Lá está João num dos bancos da única praça da cidade. O que será que João está fazendo ali? E parece falar sozinho:

- E, João... sete anos de vida. O que você vai ser quando crescer? E o

\footnotetext{
${ }^{3}$ A situação inicial é uma das funções identificadas no livro Morfologia do conto maravilhoso, de Vladimir Propp. Todas as funções serão identificadas, no texto, com o recurso de destaque em itálico. 
próprio João responde, enlevado e resoluto:

- Jornalista, João... jornalista (COPETTI, 2002, p. 8).

A cadelinha Trindade surge na narrativa exercendo uma função importante, a de doador, personagem introduzido para ajudar o herói. Seu aparecimento no texto é acompanhado também pelo primeiro suspense, pois não se sabe qual será a reação do garoto no momento de contato com a cadelinha. Há duas possibilidades: uma a de o menino rejeitar a presença do animal, e a outra a aceitação da cadela por parte do garoto. Tal ajuda consiste em amenizar a solidão por fazer companhia ao menino, segundo o fragmento a seguir:

\footnotetext{
Quando o menino se mexeu acabou por assustar a cachorra que abriu os olhos preguiçosamente, coçou o pescoço e com olhos de puro companheirismo observou João por alguns segundos e, em seguida, começou a lambê-lo de forma amigável. Formou-se ali um acordo silencioso de amizade profunda para todo o sempre (COPETTI O, 2002, p. 10).
}

Dando continuidade à análise, é possível perceber a função reação do herói. No conto em estudo, o herói não reage contra o agressor, mas sim a favor do doador. Isso é percebido a partir do momento em que o menino faz um pacto de companheirismo com o animal. Após esse primeiro instante, o garoto poeta teve companhia para suas andanças e aventuras. Vejamos o fragmento a seguir:

E João dormiu. Sentiu frio à noite e teve sonhos estranhos. Quando o dia já ia amanhecer, sentiu os pés esquentando e teve sono tranquilo até o raiar do sol. Ao acordar, levou um susto do tamanho de um cachorro, pois junto aos seus pés, dormia tranquila uma cadela vira-lata meio pelada e muito mal cuidada (COPETTI, 2002, p. 10).

Acompanhando ainda o desenrolar do texto, observa-se a função denominada fornecimento - recepção do meio mágico, que implica na realização de um dom 
extraordinário qualificador do herói. No conto Um Fantástico Mundo João, o dom extraordinário é a capacidade de expressar-se através das declamações de poesias criadas pelo garoto. O poeta Carlos Drummond de Andrade, citado no livro 100 anos de poesia, afirma que foi mais poeta pelo desejo e pela necessidade de exprimir sensações e emoções que perturbavam seu espírito e causavam angústia (RODRIGUES e MAIA, 2001, p.119). Aqui, o menino poeta também usa a poesia para preencher seus vazios e dessa forma transformar os dias sombrios em dias de alegrias:

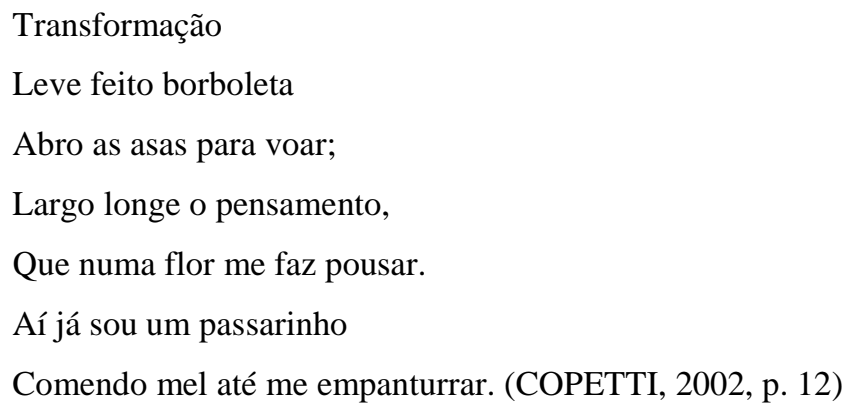

Como foi dito anteriormente, percebe-se a alteração de algumas funções neste livro, que é uma inovação por parte dos autores. Isso acontece de forma a mostrar primeiro o combate do menino contra o medo das adversidades às quais é submetido para depois chegar ao local onde está o seu objeto de busca. Essa inversão de função do personagem pode ser confirmada através do fragmento a seguir:

Aquele ir e vir de pessoas era justamente na Biblioteca que observava todos
os dias cheio de curiosidade. Então, num piscar de olhos, João encheu de ar
os pulmões, olhou significativamente para Trindade e tomou a decisão.
Segurando a cadelinha por uma corda, marchou decidido rumo à biblioteca (COPETTI, 2002, p. 14).

A décima quinta função de Propp, deslocamento espacial, fica bem evidente. $\mathrm{O}$ herói é transportado ao local onde se encontra o objeto de sua busca. Dessa forma, João abastece-se de coragem e resolve finalmente entrar na biblioteca tão observada por ele a 
fim de explorar seus recantos.

Puxando Trindade, ultrapassou o portãozinho verde-água e adentrou a Biblioteca com o coração aos pulos. Ficou embevecido com aquele mundo tão igual a um dos mundos que ele tinha na cabeça. Olhava tudo com êxtase e voracidade: as cortinas das janelas, as estantes lotadas de livros, cada um com capas e figuras mais lindas que as outras (COPETTI, 2002, p.14).

Com a continuação da história apresenta-se um segundo momento de muita tensão. Este se dá na hora em que João estende a mão para pegar um livro na estante da biblioteca, e aí sua mão é agarrada grosseiramente enquanto é acusado de ter derramado refrigerante em um dos livros de Monteiro Lobato. “- Foi esse pestinha e seu cachorro pulguento! João levou um susto, mas entendeu que estava sendo acusado de algo. Tentou se defender: “- Eu não...” (COPETTI, 2002, p. 20). Neste instante, o menino sente-se injustiçado e indefeso, com a interferência da Nana, diretora da biblioteca, personagem que, no esquema funcional de Vladimir Propp, funciona como Doador. Algo interessante que merece destaque é a presença de dois doadores. Primeiro, a cadelinha Trindade, e segundo a personagem Nana. Esta, por sua vez, exerce, além do papel de doador, o importante papel de fada madrinha. Surge também a bruxa Gorete, elemento muitíssimo comum nos contos tradicionais. Esta aparece na narrativa para complicar a vida do herói, mas, de certa forma, é desmascarada e punida. A cadela Trindade, apesar de ser uma personagem secundária, aparece a todo o momento no texto com uma importância bem maior que as outras três crianças: Ana Paula, Carol e Hilandre, os novos amigos de João.

Outro ponto observado neste livro é a função de salvamento, pois é a própria poesia que preenche os vazios do jovem herói. Dessa forma, transfere-se para a tarefa de transformar as tristezas por mais intensas e profundas que sejam em esperança e alegria. João declamava poesia dia e noite e tinha como plateia a cadela Trindade, o sol, as estrelas e a lua. 


\section{Poema da Noite}

Chega a noite cheia de sombras.

Vem encher de medo meu coração- menino

Foi-se a ciranda, não há brincadeiras de roda,

Nem pai, nem mãe...

Nem meninas pulando de corda.

Um ronco no estômago...

Um relâmpago no céu

E a noite, como um véu,

Encobre a minha sozinhês (COPETTI, 2002, p.13).

É mostrada ainda a marca do herói. Ela não é uma marca física, mas sim a coragem, visível no perfil do menino e esta faz com que o garoto consiga realizar seus sonhos. A vitória acontece a partir do momento em que o garoto vence o medo e finalmente entra na biblioteca e a partir daí tudo se modifica. João fica deslumbrado com o que vê e, sem ter noção do que fazer, observa tudo em silêncio na tentativa de compreender aquele mundo tão novo e tão fantástico. Após bastante tempo de luta nosso herói finalmente chega ao local desejado e isso o faz sentir-se extremamente feliz. Logo em seguida percebe-se a função reparação do dano ou carência. Neste caso, a missão do herói foi cumprida a partir da entrada do menino na biblioteca.

Assim, resgata-se o equilíbrio, já bem no final do texto, quando o jovem, além de ser inocentado da acusação injusta, é adotado pela diretora da biblioteca e ganha um cargo de recepcionista daquele local. A partir daí, João volta a expressar-se saudando os visitantes.

A vigésima sexta função de Propp é determinada como realização da tarefa. Porém, no conto em análise, a única pessoa capaz de realizar tal tarefa é o próprio João. É aí o momento exato dessa travessia, o sair da rua para adentrar em um ambiente cheio de surpresas, como é o caso da biblioteca, capaz de fazer uma reviravolta em sua vida e também revelar a capacidade da poesia em transformar o espírito de um poeta.

Através da adoção do garoto pela diretora da Biblioteca, João passou a ser uma pessoa de nova aparência. Propp denomina isso de transfiguração. Somente na 
penúltima função castigo ou punição é que se pôde ver que o agressor foi finalmente vencido, e o menino recebeu a valiosa retribuição.

Se fôssemos fazer aqui uma análise sociológica, certamente teríamos elementos suficientes, mas não é essa a intenção. Apesar de ser possível perceber neste livro, mesmo de modo muito sutil e delicado, uma crítica social às autoridades governamentais e à sociedade de um modo geral, que não cumprem seus papéis de protegerem e propiciar a educação às crianças. O personagem João na verdade representa todas essas crianças que perambulam pelas ruas sem frequentar escolas e sem perspectivas de uma vida e um futuro decente. Em Um Fantástico Mundo João o vilão não é somente Gorete, que impede o menino de pegar um livro na prateleira da biblioteca, mas também a pobreza, a falta de moradia, a ausência da família, o frio intenso nas noites longas e, principalmente, a falta de oportunidade de ir à escola para aprender a ler não só os livros, mas o mundo ao seu redor com toda a sua complexidade.

Finalmente, pode-se concluir que os motivos presentes na tradição oral e nos contos maravilhosos continuam encantando os leitores de hoje porque são universais. Através do conto em estudo foi possível perceber a capacidade das narrativas em atravessar vários discursos, sejam históricos, religiosos ou políticos, vindos de lugares e épocas distintas, para retornarem em outro momento, embora, muitas vezes, com novas roupagens. Além disso, os elementos narrativos encontrados na produção dos discentes como: personagens, sequência narrativa, tempo, espaço e outros estão na realidade no imaginário. E isso é percebido através da forma que o texto foi escrito, lançando mão da sequência sugerida por Propp. Procuram inovar com a exclusão e até mesmo a alteração da ordem de algumas funções sem, no entanto ${ }_{2}$ comprometer o curso da trama. Essa inovação na estrutura da narrativa mostra um processo de adaptação do conto tradicional a um novo tempo e a um novo espaço.

\section{REFERÊNCIAS}


ALDRIGUE, A. C. S. Memória e Cultura Popular: vozes da intertextualidade em Contos populares do Nordeste Brasileiro. Tese (Doutorado em Linguística e Língua Portuguesa) - Faculdade de Ciências e Letras, Universidade Estadual Paulista. Araraquara, 1998.

ARIES, Philippe. História social da criança e da família. Rio de Janeiro: Zahar,1978.

BAKHTIN, M. M. Problemas da poética de Dostoiévski. Trad. Paulo Bezerra. 4 ed. Rio de Janeiro: Forense Universitária, 2008.

BORGES, J. L. Obras completas. Buenos Aires: Emecé Editores, 1984.

CAMPBELL, J. O Herói de Mil Faces. Tradução de Adail Ubirajara Sobral. 10. ed. Revisada. São Paulo: Cultrix, 1997.

CARVAlHO. D. M. S. Entre o Oral e o Escrito: O conto numa Comunidade Amazônica. Dissertação (Mestrado em Estudo Literário) - Curso de Pós-Graduação em Letras. Faculdade de Ciências e letras, Universidade Estadual Paulista. Araraquara, 2001 .

A presença da literatura oral no vale do Juruá: Manifestações folclóricas e identidade. Rio de Janeiro, Papel Virtual, 2005.

CASCUDO. L. C. Literatura Oral no Brasil. 3 ed. São Paulo: Itatiaia, 1984.435 p.

. Contos Tradicionais do Brasil. 8 ed. São Paulo: Global, 2000.

CHEVALIER, J. e GHEERBRANT, A. Dicionário de símbolos: mitos, sonhos, costumes, gestos, formas, figuras, cores, números. Trad. Vera da Silva Costa e Silva. 24 ed. Rio de Janeiro: José Olympio, 2009.

COPETTI, A. S. A. [Et al]. Um fantástico mundo João. Cruzeiro do Sul: UFAC, 2002. COSTA, M. J. S. M. O conto como revelação. In: Trajetória de uma expressão amazônica: o encanto do desencanto em Florentina Esteves. São Paulo: All Print Editora, 2013. P. 57-78.

DURAND, G. As estruturas antropológicas do imaginário. Tradução Hélder Godinho. São Paulo: Martins Fontes, 1997.

HELD, J. O imaginário no poder: as crianças e a literatura fantástica. Trad. Carlos Rizzi. São Paulo: Summus, 1980. 
HILLMAN, J. Uma investigação sobre a imagem. An inquiry into image. Spring york, 1977.

PROPP, V. I. Morfologia do Conto Maravilhoso. Rio de Janeiro: ForenseUniversitária, 1984.

RIBEIRO, F. Aventuras na história: quem tem medo do Lobo Mau. Abril. p.54-57, 2005.

RODRIGUES, C. e MAIA, A. 100 anos de poesia: Um panorama da poesia brasileira no século XX. Volume I. Rio de Janeiro: Verso Edições, 2001.

SABINO, F. O grande Mentecapto. São Paulo: Record, 1986.

TEIXEIRA, M.C.S. e ARAÚJO, A. F. Gilbert Durand: imaginário e educação. Niterói: Intertexto, 2011. 